\title{
Theoretical Study of Decomposition Pathways for HArF and HKrF
}

\author{
Galina M. Chaban*
}

NASA Ames Research Center, Mail Stop T27B-1, Moffett Field, CA 94035-1000, USA

Jan Lundell

Department of Chemistry, University of Helsinki, P.O.Box 55 (A.I.Virtasen aukio 1), FIN-00014, Finland

R. Benny Gerber

Department of Physical Chemistry, Hebrew University, Jerusalem 91904, Israel; and Department of Chemistry, University of California, Irvine, CA 92697-2025, USA

* Corresponding author, e-mail address: chabanomas.nasa.gov 


\begin{abstract}
To provide theoretical insights into the stability and dynamics of the new rare gas compounds HArF and $\mathrm{HKrF}$, reaction paths for decomposition processes $\mathrm{HRgF} \rightarrow \mathrm{Rg}+$ $\mathrm{HF}$ and $\mathrm{HRgF} \rightarrow \mathrm{H}+\mathrm{Rg}+\mathrm{F}(\mathrm{Rg}=\mathrm{Ar}, \mathrm{Kr})$ are calculated using ab initio electronic structure methods. The bending channels, $\mathrm{HRgF} \rightarrow \mathrm{Rg}+\mathrm{HF}$, are described by single-configurational MP2 and CCSD(T) electronic structure methods, while the linear decomposition paths, $\mathrm{HRgF} \rightarrow \mathrm{H}+\mathrm{Rg}+\mathrm{F}$, require the use of multi-configurational wave functions that include dynamic correlation and are size extensive. HArF and $\mathrm{HKrF}$ molecules are found to be energetically stable with respect to atomic dissociation products $(\mathrm{H}+\mathrm{Rg}+\mathrm{F})$ and separated by substantial energy barriers from $\mathrm{Rg}+\mathrm{HF}$ products, which ensure their kinetic stability. The results are compatible with experimental data on these systems.
\end{abstract}




\section{Introduction}

Very recently, a first stable chemically-bound compound of argon, HArF, was prepared experimentally in a low-temperature Ar matrix ${ }^{1,2}$. The corresponding krypton compound, $\mathrm{HKrF}$, is also new and its preparation has just been reported ${ }^{3}$. Several theoretical studies have been performed that addressed the electronic structure and the nature of bonding in these molecules ${ }^{4-7}$, as well as their vibrational spectroscopy both in gas phase $^{5,7}$ and in rare-gas matrix environments ${ }^{8}$. Transition states for $\mathrm{HRgF} \rightarrow \mathrm{HF}+\mathrm{Rg}(\mathrm{Rg}=$ $\mathrm{Ar}, \mathrm{Kr}$ ) reactions have been obtained previously ${ }^{4}$. In addition, stability of HArF with respect to the two dissociation channels $(\mathrm{HArF} \rightarrow \mathrm{H}+\mathrm{Ar}+\mathrm{F}$ and $\mathrm{HArF} \rightarrow \mathrm{HF}+\mathrm{Ar}$ ) has been considered by studying approximate minimum-energy reaction paths and energetics of dissociation products ${ }^{6,7}$. However, true minimum-energy paths for these processes have never been calculated. This study intends to fill this gap by performing intrinsic reaction coordinate (IRC) calculations following the minimum energy paths (MEPs) that connect $\mathrm{HArF}$ and $\mathrm{HKrF}$ compounds to their dissociation products. Knowledge of reaction paths is very important for understanding formation and decomposition dynamics of these novel rare-gas compounds. A similar study has been recently performed for $\mathrm{HHeF}$ compound ${ }^{9}$ that showed the importance of calculating reaction paths using the IRC method. By theoretical predictions, the species HHeF is a (first) chemically-bound compound of He in the electronic ground state ${ }^{4,5,9}$ though this is not yet experimentally confirmed. HHeF was found to be a metastable species separated from $\mathrm{He}+\mathrm{HF}$ and $\mathrm{H}+\mathrm{He}+\mathrm{F}$ dissociation 
products by low $(8-10 \mathrm{kcal} / \mathrm{mol})$ barriers at the level of second order perturbation theory. Tunneling rate to decomposition of HHeF through these barriers has been estimated, and a relatively long lifetime (on the order of $120 \mathrm{ps)} \mathrm{to} \mathrm{He}+\mathrm{HF}$ decomposition has been predicted $^{9}$. A study by Takayanagi and Wada at the multi-reference CI level ${ }^{10}$ showed lower (about $5 \mathrm{kcal} / \mathrm{mol}$ ) barrier height for $\mathrm{HHeF} \rightarrow \mathrm{H}+\mathrm{He}+\mathrm{F}$ reaction and shorter lifetime for HHeF compound (only $157 \mathrm{fs}$ ). This shows a great sensitivity of the predicted dynamics and behavior of the rare-gas compounds on the calculated potential energy surface.

Although HArF and $\mathrm{HKrF}$ are more stable than $\mathrm{HHeF}$, reliable estimation of the pathways between minima and dissociation products is crucial for understanding both dissociation and formation dynamics for these compounds. The calculated reaction paths will help future studies of the influence of temperature and IR excitation on decomposition dynamics and tunneling lifetimes of $\mathrm{HArF}$ and $\mathrm{HKrF}$ compounds.

\section{Computational methods}

Equilibrium structures of $\mathrm{HArF}$ and $\mathrm{HKrF}$ minima and of transition states (TS) leading to $\mathrm{HF}+\mathrm{Ar}(\mathrm{Kr})$ products were computed at the second-order Møller-Plesset (MP2) level of electronic structure theory ${ }^{11}$ with augmented correlation-consistent valence triple- $\zeta$ (aug-cc-pVTZ) basis set ${ }^{12-14}$. The same level of theory was used to obtain the minimum energy paths (MEPs) leading from the equilibrium structures to the energetically more stable products $\operatorname{Ar}(\mathrm{Kr})+\mathrm{HF}$. These MEPs were calculated using the Intrinsic Reaction 
Coordinate method (IRC) ${ }^{15}$ with the second order Gonzalez-Schlegel algorithm ${ }^{16}$ and a step size of $0.1 \mathrm{amu}{ }^{1 / 2}$ bohr. Single point energies were estimated along these MEPs at the higher level coupled-cluster method $\operatorname{CCSD}(\mathrm{T})^{17}$. Stationary points optimizations and IRC calculations were carried out using the electronic structure package GAMESS $^{18}$, while $\operatorname{CCSD}(\mathrm{T})$ single-point energies were computed using GAUSSIAN98 ${ }^{19}$.

The IRC paths to $\mathrm{H}+\mathrm{Rg}+\mathrm{F}$ were studied using CASSCF wave functions that included 16 active electrons and 9 active orbitals. This is the full-valence active space (excluding valence d-orbitals) and is denoted as $\operatorname{MCSCF}(16,9)$. The same, aug-cc-pVTZ, basis set was used as for the bending ( $\mathrm{HF}+\mathrm{Rg}$ ) channel. The potential energy points along the IRC were computed using several methods that include dynamic electron correlation effects: multi-reference second order perturbation theory CASPT2 ${ }^{20}$, internally contracted multi-reference configuration interaction $\mathrm{MRCI}^{21}$, and size-extensive modifications of MRCI: multi-reference averaged coupled-pair functional $\mathrm{MR}-\mathrm{ACPF}^{22}$ and multi-reference averaged quadratic coupled-cluster AQCC ${ }^{23}$ methods. CASPT2, MRCI, MR-ACPF, and MR-AQCC calculations are all based on $\operatorname{MCSCF}(16,9)$ reference wave functions and performed using MOLPRO electronic structure package ${ }^{24}$.

\section{Results and discussion}

The reaction paths for the $\mathrm{HArF} \rightarrow \mathrm{Ar}+\mathrm{HF}$ and $\mathrm{HKrF} \rightarrow \mathrm{Kr}+\mathrm{HF}$ dissociation processes are shown in Figs. 1 and 2. The IRC paths were obtained at the single- 
configurational MP2/aug-cc-pVTZ level of theory. The validity of the single-configurational approach for this dissociation channel was tested in our previous study for a similar reaction path for $\mathrm{HHeF}^{9}$. It was shown that multi-configurational second order perturbation theory (CASPT2) gave virtually the same potential values along the reaction path as singleconfigurational MP2. Therefore, we assume that single-configurational MP2 approach should be valid in the case of $\mathrm{HRgF} \rightarrow \mathrm{Rg}+\mathrm{HF}$ dissociation channels also for $\mathrm{Ar}$ and $\mathrm{Kr}$. To test the MP2 reaction path further, we have calculated $\operatorname{CCSD}(\mathrm{T})$ potential energy points along the MP2 reaction paths. It can be seen from Figures 1 and 2 that $\operatorname{CCSD}(\mathrm{T})$ relative energies along the IRC paths are in very good agreement with and practically indistinguishable from MP2 results. This also supports the validity of the MP2 approach for $\mathrm{HRgF} \rightarrow \mathrm{Rg}+\mathrm{HF}$ dissociation channels. The transition states found in this study are 23.7 and $32.1 \mathrm{kcal} / \mathrm{mol}$ above the equilibrium structures of $\mathrm{HArF}$ and $\mathrm{HKrF}$, respectively. These are slightly lower than predicted by Wong (Ref. 4): 28.0 and $34.6 \mathrm{kcal} / \mathrm{mol}$. The configurations corresponding to the transition states are shown in Fig. 3. The IRC paths in the beginning correspond approximately to the motion along the bending coordinate of HArF (HKrF). At later stages, the rare gas atom assumes a closed shell electronic structure, and the H-F bond forms (see Fig. 1). The dissociation products ( $\mathrm{Rg}+\mathrm{HF}$ ) are lower in energy than $\mathrm{HRgF}$ by $134 \mathrm{kcal} / \mathrm{mol}$ and $112 \mathrm{kcal} / \mathrm{mol}$ in case of Ar and $\mathrm{Kr}$ respectively. However, relatively high barriers to these dissociation products make both $\mathrm{HArF}$ and $\mathrm{HKrF}$ 
compounds kinetically stable. This is compatible with the experimental preparation of both HArF and $\mathrm{HKrF}^{1-3}$.

The reaction paths for the 3-body decomposition channels $\mathrm{HArF} \rightarrow \mathrm{H}+\mathrm{Ar}+\mathrm{F}$ and $\mathrm{HKrF} \rightarrow \mathrm{H}+\mathrm{Kr}+\mathrm{F}$ are shown in Figs. 4 and 5 . The dissociation motion in this case is collinear rather than bending. It can be seen from these figures that MCSCF method incorrectly predicts both $\mathrm{HArF}$ and $\mathrm{HKrF}$ to be energetically higher than atomic dissociation products. Obviously, more accurate methods that include dynamic correlation are necessary to obtain more reliable results for these dissociation channels. Although the situation is greatly improved at the MRCI level as compared to MCSCF, this level still does not provide quantitatively correct 3-body dissociation paths and predicts dissociation limits too low in energy with respect to $\mathrm{HRgF}$ minima. CASPT2 calculations predict both dissociation products and transition states at higher energies with respect to HRgF minima than MRCI. At the level of CASPT2, the dissociation products are predicted to be about 6.8 and $26.4 \mathrm{kcal} / \mathrm{mol}$ above the $\mathrm{HArF}$ and $\mathrm{HKrF}$ minima respectively. This quite significant difference between $\mathrm{MRCI}$ and CASPT2 results has prompted us to test additional methods that combine advantages of both MRCI and CASPT2: size extensive multi-reference ACPF and AQCC methods. As can be seen from Figures 4 and 5, these methods give energies, which are in between those of MRCI and CASPT2. They predict both HArF and HKrF compounds below their dissociation products $\mathrm{H}+\mathrm{Rg}+\mathrm{F}$, which is an encouraging result. The binding energies for HArF are 0.2 and $1.8 \mathrm{kcal} / \mathrm{mol}$ from AQCC and ACPF 
respectively. This is consistent with experimental results ${ }^{1-2}$ that show that HArF is stable with respect to $\mathrm{H}+\mathrm{Ar}+\mathrm{F}$, but the binding energy is not very large. The binding energies for $\mathrm{HKrF}$ are 19.8 and $21.2 \mathrm{kcal} / \mathrm{mol}$ at the $\mathrm{AQCC}$ and $\mathrm{ACPF}$ levels respectively. These are somewhat lower, but not very different from the CASPT2 result. It should be noted that there is a sizable barrier for the formation of $\mathrm{HArF}$ from atomic $\mathrm{H}+\mathrm{Ar}+\mathrm{F}$ fragments, about $10-11 \mathrm{kcal} / \mathrm{mol}$. This barrier appears to be too high since the HArF can be formed upon annealing of solid argon matrix at about $18 \mathrm{~K}^{1}$. On the other hand, the large barrier from HArF towards its collinear dissociation channel seems reasonable in the light of annealing experiments of $\mathrm{HArF}$ in solid $\mathrm{Ar}^{2}$, in which the IR spectrum of $\mathrm{HArF}$ in $\mathrm{a}$ thermally relaxed environment is visible until the sample evaporates above $40 \mathrm{~K}$. In the case of $\mathrm{HKrF}$ the dissociation barrier of the collinear $\mathrm{H}+\mathrm{Kr}+\mathrm{F} \rightarrow \mathrm{HKrF}$ channel is much lower, about $5-6 \mathrm{kcal} / \mathrm{mol}$. This correlates well with the experimental observation ${ }^{3}$ of $\mathrm{HKrF}$ formation in one of the sites of $\mathrm{Kr}$ matrix at about $13 \mathrm{~K}$, which suggests a reaction with a very low barrier. It can be concluded that potential energy surfaces for $\mathrm{HRgF} \rightarrow \mathrm{H}+\mathrm{Rg}+\mathrm{F}$ dissociation channel are not easy to describe correctly for such unusual rare-gas compounds as HArF and HKrF. MCSCF and internally contracted MRCI methods do not give qualitatively correct energetics for this reaction channel. On the other hand, CASPT2, MRAQCC, and MR-ACPF calculations seem to reproduce the experimentally observed features of formation of these two molecules qualitatively correctly and could be considered a rather good starting point for understanding both dissociation and formation dynamics on 
molecular level in solid hosts. Work on tunneling decomposition and on formation dynamics of $\mathrm{HArF}, \mathrm{HKrF}$ in the corresponding $\mathrm{Ar}$ and $\mathrm{Kr}$ matrices is currently under way ${ }^{25}$.

\section{Conclusions}

Minimum-energy reaction paths are computed for decomposition processes HRgF $\rightarrow \mathrm{Rg}+\mathrm{HF}$ and $\mathrm{HRgF} \rightarrow \mathrm{H}+\mathrm{Rg}+\mathrm{F}(\mathrm{Rg}=\mathrm{Ar}, \mathrm{Kr})$ using ab initio electronic structure potentials and intrinsic reaction coordinate (IRC) method. Although some of these reactions have been studied previously, true minimum energy paths have not been obtained before. The calculated energetics for $\mathrm{HRgF} \rightarrow \mathrm{Rg}+\mathrm{HF}$ reactions (barrier heights and exothermicities) are in good agreement with previous studies. While the $\mathrm{HRgF} \rightarrow \mathrm{Rg}+\mathrm{HF}$ channels are described reasonably well by single-configurational MP2 and $\operatorname{CCSD}(\mathrm{T})$ electronic structure methods, investigation of the linear decomposition paths (HRgF $\rightarrow \mathrm{H}+$ $\mathrm{Rg}+\mathrm{F}$ ) is more challenging and requires use of multi-configurational wave functions, as well as dynamic correlation treatment. Furthermore, different methods that account for dynamic correlation (CASPT2 and $\mathrm{MRCI}$ ) give quite different results for this reaction path. It appears that the results obtained using size extensive multi-reference ACPF and AQCC methods provide the most reliable predictions in this case. The shapes of the reaction paths for HArF and $\mathrm{HKrF}$ dissociation processes are obtained in this study for the first time and should be useful for future studies of the influence of temperature and IR excitation on decomposition dynamics and tunneling lifetimes of $\mathrm{HArF}$ and $\mathrm{HKrF}$ compounds. 


\section{Acknowledgements}

We would like to thank Dr. Chris Dateo for useful comments upon reading the manuscript. Work at UC Irvine was supported by National Science Foundation (Grant CHE-0101199, to RBG). Work at the Hebrew U. was partly supported by the DFG, Germany (under project SFB450). Financial support from the Academy of Finland and the Finnish Culture Foundation to JL is gratefully acknowledged.

\section{References}

1. Khriachtchev, L.; Pettersson, M.; Runeberg, N.; Lundell, J.; Räsänen, M. Nature 406, $874(2000)$.

2. Khriachtchev, L.; Pettersson, M.; Lignell, A; Räsänen, M. J. Amer. Chem. Soc. 123, $8610(2001)$.

3. Pettersson, M.; Khriachtchev, L.; Lignell, A.; Räsänen, M.; Bihary, Z.; Gerber, R. B. J. Chem. Phys. 116, 2508 (2002).

4. Wong, M. W. J. Am. Chem. Soc. 122, 6289 (2000).

5. Lundell, J.; Chaban, G. M.; Gerber, R. B. Chem. Phys. Lett. 331, 308 (2000).

6. Pettersson, M.; Lundell, J.; Räsänen, M. J. Chem. Phys. 102, 6423 (1995).

7. Runeberg, N.; Pettersson, M.; Khriachtchev, L.; Lundell, J.; Räsänen, M. J. Chem. Phys. 114, 836 (2001). 
8. Bihary, Z.; Chaban, G. M.; Gerber, R. B. J. Chem. Phys. 116, 5521 (2002).

9. Chaban, G. M.; Lundell, J.; Gerber, R. B. J. Chem. Phys. 115, 7341 (2001).

10. Takayanagi, T; Wada, A. Chem. Phys. Lett. 352, 91 (2002).

11. J. A. Pople, J. S. Binkley, and R. Seeger. Int. J. Quantum Chem, 10, 1 (1976).

12. T. H. Dunning, Jr. J. Chem. Phys., 90, 1007 (1989).

13. R. A. Kendall, T. H. Dunning, Jr. and R. J. Harrison, J. Chem. Phys., 96, 6769 (1992).

14. D. E. Woon and T. H. Dunning, Jr. J. Chem. Phys. 98, 1358 (1993).

15. Baldridge, K. K., Gordon, M. S., Steckler, R., Truhlar, D. G. J. Phys. Chem. 93, $5107-$ 5119 (1989).

16. Gonzalez, C., Schlegel, H. B. J. Phys. Chem. 94, 5523-5527 (1990).

17. Raghavachari, K.; Trucks, G. W.; Pople, J. A.; Head-Gordon, M. Chem. Phys. Lett. 157, 479 (1989).

18. Schmidt, M. W.; Baldridge, K. K.; Boatz, J. A.; Elbert, S. T.; Gordon, M. S.; Jensen, J. H.; Koseki, S.; Matsunaga, N.; Nguyen, K. A.; Su, S.; Windus, T. L.; Dupuis, M.; Montgomery, J. A. J. Comput. Chem. 14, 1347-1363 (1993).

19. Gaussian 98, Revision A.11, M. J. Frisch, G. W. Trucks, H. B. Schlegel, G. E. Scuseria, M. A. Robb, J. R. Cheeseman, V. G. Zakrzewski, J. A. Montgomery, Jr., R. E. Stratmanin, J. C. Burant, S. Dapprich, J. M. Millam, A. D. Daniels, K. N. Kudin, M. C. Strain, O. Farkas, J. Tomasi, V. Barone, M. Cossi, R. Cammi, B. Mennucci, C. Pomelli, 
C. Adamo, S. Clifford, J. Ochterski, G. A. Petersson, P. Y. Ayala, Q. Cui, K. Morokuma, P. Salvador, J. J. Dannenberg, D. K. Malick, A. D. Rabuck, K.

Raghavachari, J. B. Foresman, J. Cioslowski, J. V. Ortiz, A. G. Baboul, B. B. Stefanov, G. Liu, A. Liashenko, P. Piskorz, I. Komaromi, R. Gomperts, R. L. Martin, D. J. Fox, T. Keith, M. A. Al-Laham, C. Y. Peng, A. Nanayakkara, M. Challacombe, P. M. W. Gill, B. Johnson, W. Chen, M. W. Wong, J. L. Andres, C. Gonzalez, M. Head-Gordon, E. S. Replogle, and J. A. Pople, Gaussian, Inc., Pittsburgh PA, 2001.

20. H.-J. Werner. Mol. Phys. 89, 645 (1996).

21. H.-J. Werner and P. J. Knowles. J. Chem. Phys. 89, 5803-5814 (1988).

22. Gdanitz, R. J., and Ahlrichs, R. Chem. Phys. Lett. 143, 413 (1988).

23. Szalay, P. G. and Bartlett, R. J. Chem. Phys. Lett. 214, 481 (1993).

24. MOLPRO, a package of ab initio programs designed by H.-J. Werner and P. J. Knowles, version 2002.1, R. D. Amos, A. Bernhardsson, A. Berning, P. Celani, D. L. Cooper, M. J. O. Deegan, A. J. Dobbyn, F. Eckert, C. Hampel, G. Hetzer, P. J. Knowles, T. Korona, R. Lindh, A. W. Lloyd, S. J. McNicholas, F. R. Manby, W. Meyer, M. E. Mura, A. Nicklass, P. Palmieri, R. Pitzer, G. Rauhut, M. Schütz, U. Schumann, H. Stoll, A. J. Stone, R. Tarroni, T. Thorsteinsson, and H.-J. Werner.

25. Z. Bihary, G. M. Chaban and R. B. Gerber, to be published. 


\section{Figure Captions}

Figure 1. Minimum energy path for $\mathrm{HArF} \rightarrow \mathrm{Ar}+\mathrm{HF}$ reaction.

Figure 2. Minimum energy path for $\mathrm{HKrF} \rightarrow \mathrm{Kr}+\mathrm{HF}$ reaction.

Figure 3. Equilibrium and transition state geometries for $\mathrm{HArF}$ and $\mathrm{HKrF}$ obtained at the MP2/aug-cc-pVTZ level of theory (bond distances are given in angstroms, angles - in degrees).

Figure 4. Minimum energy path for $\mathrm{HArF} \rightarrow \mathrm{H}+\mathrm{Ar}+\mathrm{F}$ reaction.

Figure 5. Minimum energy path for $\mathrm{HKrF} \rightarrow \mathrm{H}+\mathrm{Kr}+\mathrm{F}$ reaction. 


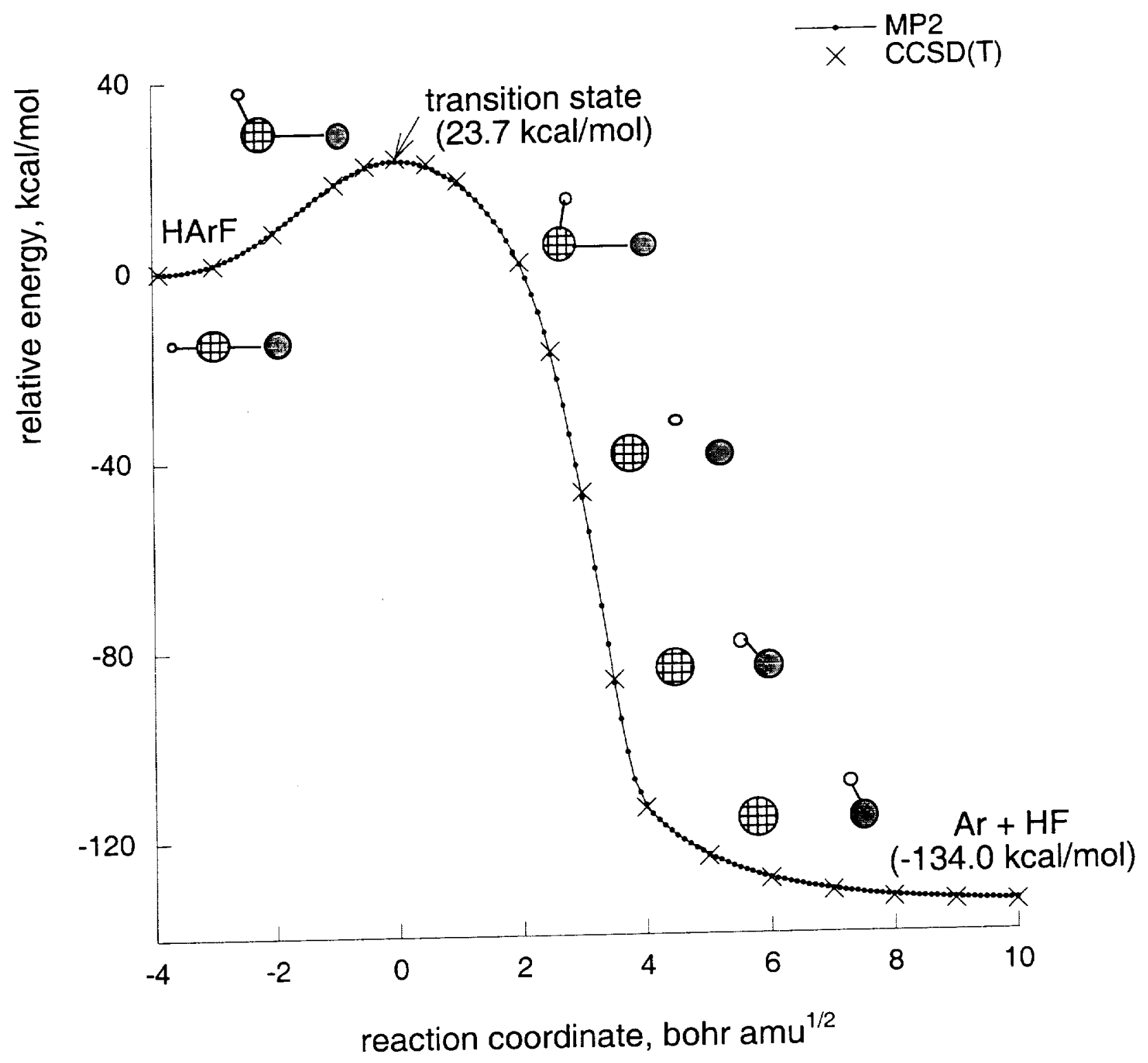




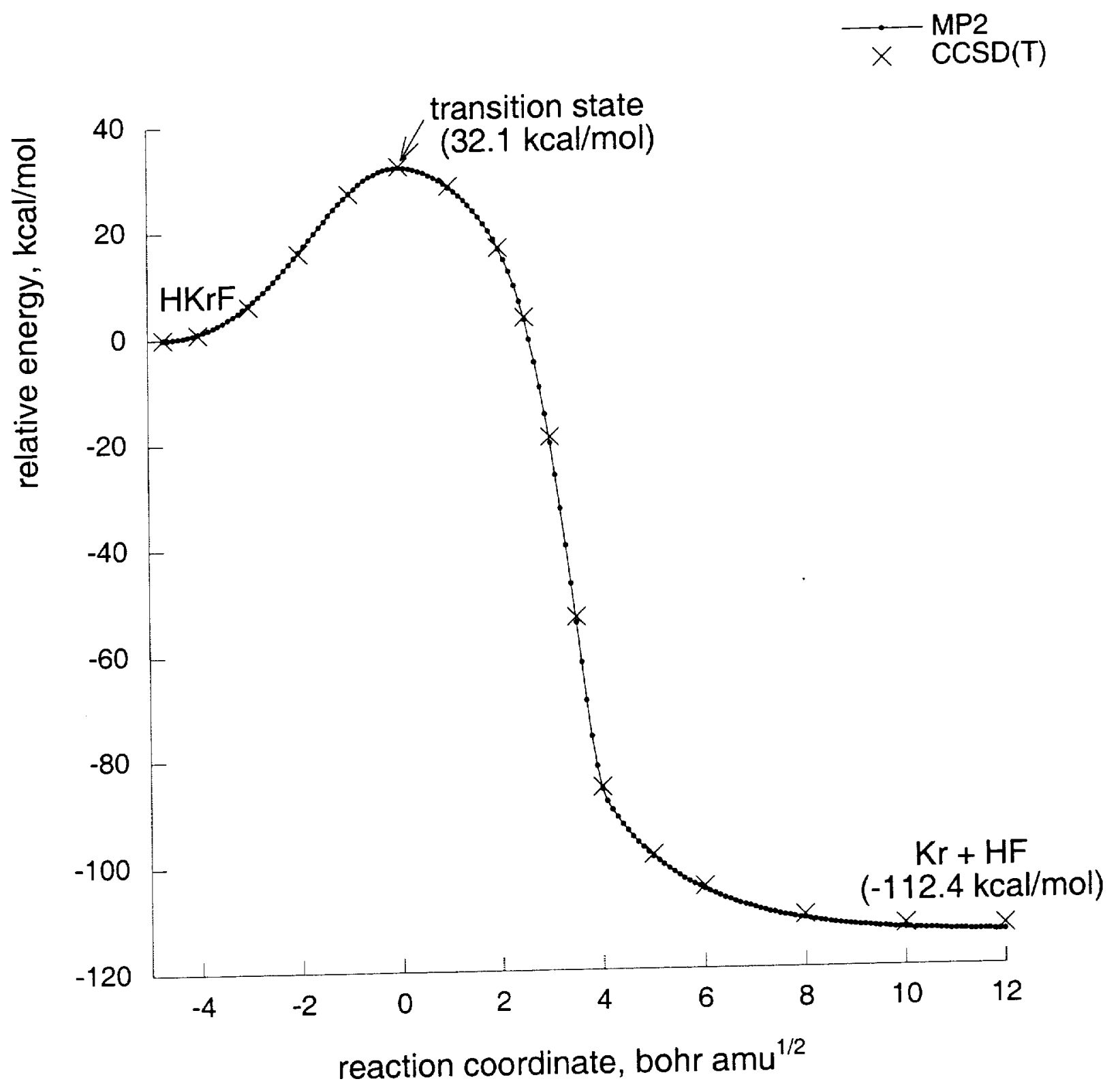

Fig. 


\section{HArF}

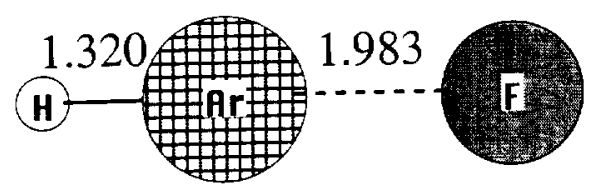

minimum

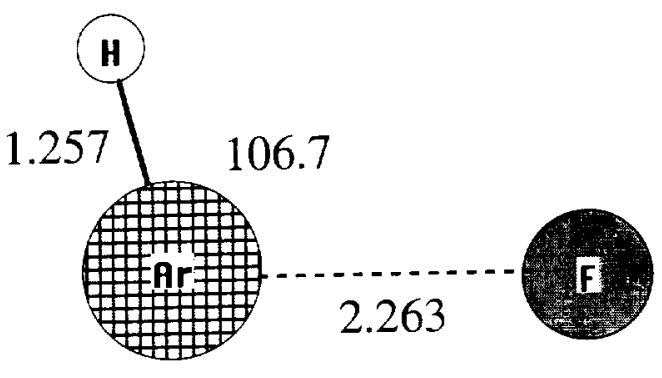

transition state
$\mathrm{HKrF}$

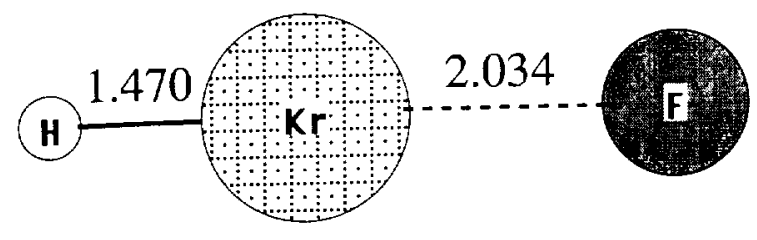

minimum

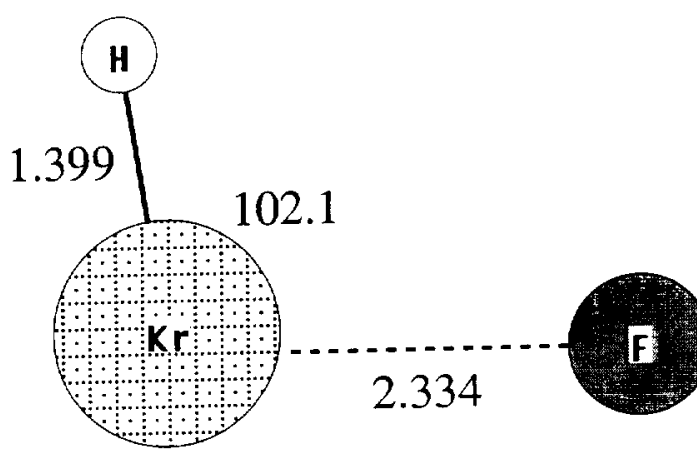

transition state 


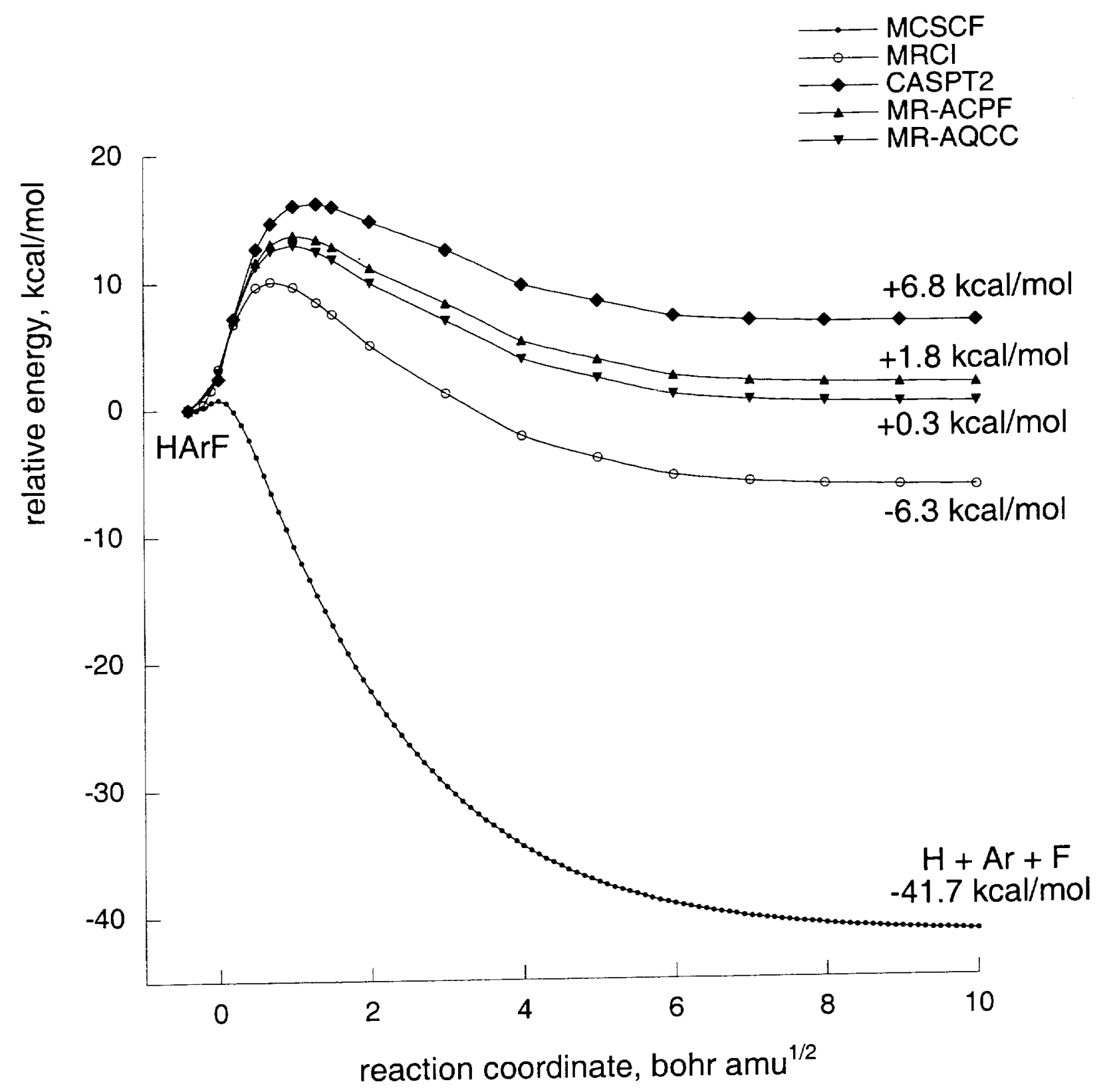




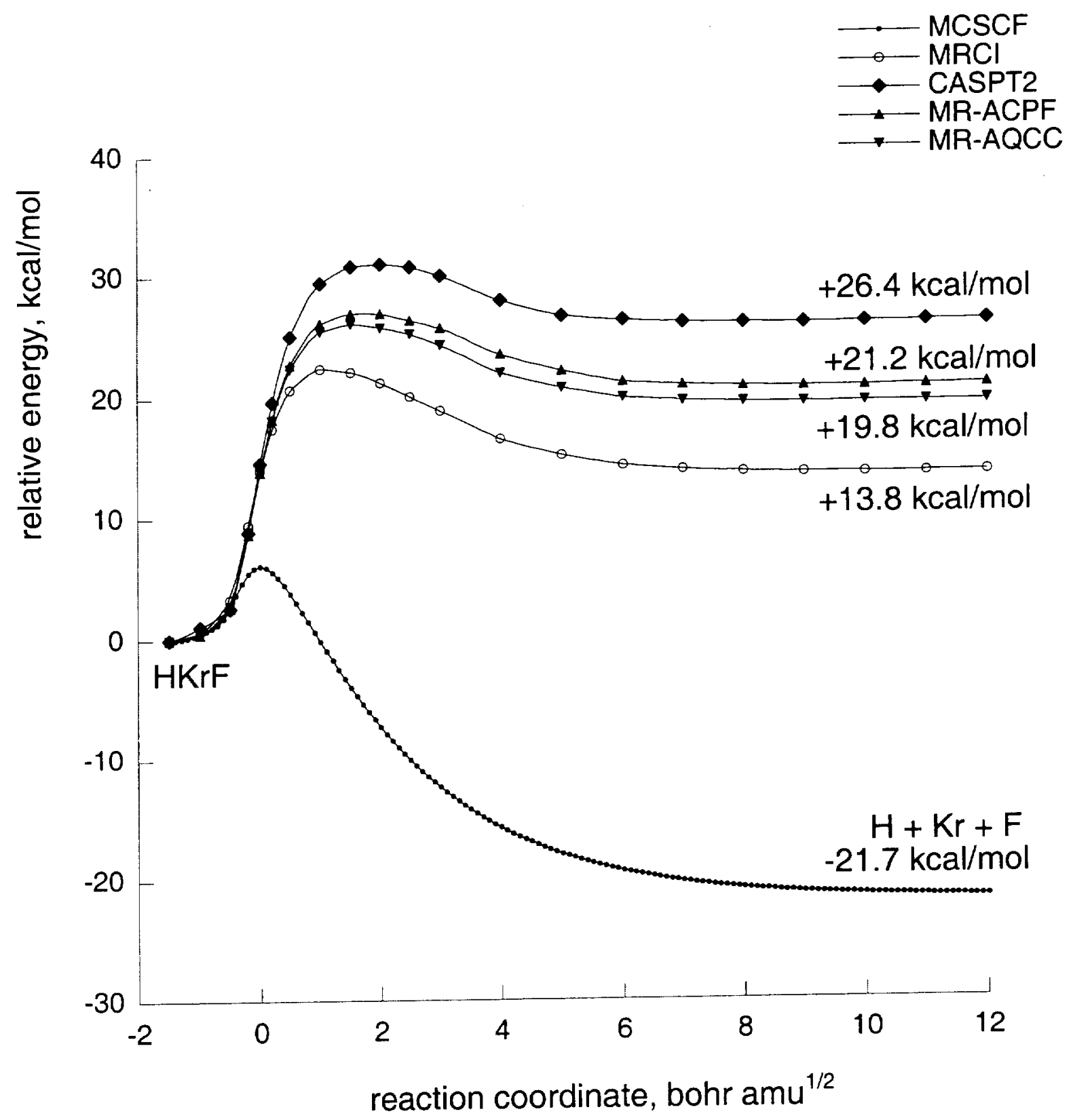

